\title{
Effect of dialectical behavior group therapy on the anxiety and depression of medical students under the normalization of epidemic prevention and control for the COVID-19 epidemic: a randomized study
}

\author{
Lizhen Liang ${ }^{1}$, Ling Feng ${ }^{2}$, Xiaoming Zheng ${ }^{3}$, Ying Wu ${ }^{1}$, Chunhua Zhang ${ }^{4}$, Jingjing $\mathrm{Li}^{5}$ \\ ${ }^{1}$ Department of General Medicine, Zhongnan Hospital of Wuhan University, Wuhan, China; ${ }^{2}$ AIDS Training Center, Zhongnan Hospital of Wuhan \\ University, Wuhan, China; ${ }^{3}$ Central Operating Room, Shiyan Taihe Hospital, Shiyan, China; ${ }^{4}$ Department of Nursing, Zhongnan Hospital of \\ Wuhan University, Wuhan, China; ${ }^{5}$ School of Mental Health and Psychological Science, Anhui Medical University, Hefei, China \\ Contributions: (I) Conception and design: L Liang; (II) Administrative support: Y Wu, C Zhang; (III) Provision of study materials or patients: L \\ Feng; (IV) Collection and assembly of data: X Zheng; (V) Data analysis and interpretation: L Liang; (VI) Manuscript writing: All authors; (VII) Final \\ approval of manuscript: All authors. \\ Correspondence to: Ying Wu. Department of General Medicine, Zhongnan Hospital of Wuhan University, Wuhan, China. \\ Email: vivian444333@qq.com; Chunhua Zhang. Department of Nursing, Zhongnan Hospital of Wuhan University, Wuhan, China. \\ Email: 1648276079@qq.com.
}

\begin{abstract}
Background During the epidemic, the mental health of college students was generally poor, especially anxiety and depression, which should be treated using counseling and intervention. This study aimed to observe the influence of dialectical behavior therapy on the anxiety and depression of medical students during the normalization of the prevention and control of the COVID-19 epidemic.

Methods: A total of 26 medical students (experimental group) were treated with dialectical behavior therapy intervention for 4 weeks. Changes in depression, anxiety, and stress levels were assessed by the Patient Health Questionnaire (PHQ-9), the Generalized Anxiety Disorder (GAD-7) scale, the Somatic Self-rating Scale (SSS), and the Perceived Stress Scale (PSS-10). This group was compared with 26 medical students (control group) without intervention.
\end{abstract}

Results: The value-added scores of the PHQ-9 ( $\mathrm{t}=2.543, \mathrm{P}=0.014)$ and GAD-7 scales $(\mathrm{t}=3.790, \mathrm{P}=0.000)$ in the experimental group were significantly higher than those in the control group, while in the SSS scale, the value-added score of the depressive symptoms subscale $(t=2.234, \mathrm{P}=0.030)$ in the experimental group was significantly higher than that of the control group. For the total score of the PSS-10 scale $(\mathrm{t}=2.435, \mathrm{P}=0.018)$, the value-added score of the experimental group was significantly higher than that of the control group.

Conclusions: The intervention of dialectical behavior therapy can effectively alleviate the depression and anxiety of medical students during the normalization of epidemic prevention and control.

Trial Registration: Chinese Clinical Trial Registry ChiCTR2100048784.

Keywords: Dialectical behavior therapy; medical students; negative emotions; epidemic

Submitted Jul 30, 2021. Accepted for publication Oct 20, 2021.

doi: 10.21037/apm-21-2466

View this article at: https://dx.doi.org/10.21037/apm-21-2466

\section{Introduction}

Currently, there is a period of normalization of prevention and control for the COVID-19 epidemic in China, and the psychological problems caused by the epidemic among college students have been highlighted. In addition to facing the crisis of the epidemic, they also have to face long and relatively closed special holidays, along with physical and mental discomfort after the start of the school year. There 
Table 1 General information of patients in the experimental and control groups

\begin{tabular}{lcc}
\hline Variable & Experimental group & Control group \\
\hline Total participants & 26 & 26 \\
Gender (male/female) & $10 / 16$ & $10 / 16$ \\
Age (years) & $20.73 \pm 1.87$ & $20.62 \pm 1.79$ \\
\hline
\end{tabular}

are various degrees of concern in terms of emotions, studies, life, and other factors (1). During the COVID-19 epidemic, the overall mental health of college students was poor, with a $26.60 \%$ overall incidence of anxiety among college students, and $21.16 \%$ of them had depression (2). In a metaanalysis investigating the prevalence of anxiety among medical students during this pandemic, the prevalence of anxiety among medical students was estimated to be $28 \%$ (3). Medical students need to cope with the emergence of anxiety and depression by scientific counseling and intervention.

Dialectical behavioral therapy (DBT) is based on cognitive behavioral therapy, combined with the dialectical thinking of Eastern Zen, and is based on the principle of dialectics, in which the dialectical relationship between normal and abnormal psychology and behavior, as well as the dialectical balance of acceptance and changes, is emphasized (4). DBT was initially used in the treatment of suicide and borderline personality disorder (5). DBT also has a good therapeutic effect on disorders such as substance abuse, eating disorders, anxiety, addiction, and severe depression, among others (6). DBT can help people use mindfulness skills in daily life to master psychological functions, recognize the self, adjust disordered emotions, establish effective interpersonal relationships, and learn how to endure the inevitable pain of life and others (7).

An activity scheme based on the anxiety and depression of medical students was designed by the application of DBT as an intervention method in this study, and the effect of DBT on improving depression and anxiety in medical students was explored during the normalization period of prevention and control of the COVID-19 epidemic. We present the following article in accordance with the CONSORT reporting checklist (available at https://dx.doi. org/10.21037/apm-21-2466).

\section{Methods}

\section{Subjects}

In May 2020, a total of 14,047 electronic questionnaires were provided to the student group of Anhui Medical University. The inclusion criteria were as follows: (I) voluntary enrollment, good health, sufficient time to participate in studies, without obvious physical disabilities, and no mental illness in first-degree relatives; (II) students did not participate in relevant psychotherapy; (III) students were diagnosed with mild to moderate depression and anxiety symptoms by the Patient Health Questionnaire (PHQ-9) and the Generalized Anxiety Disorder (GAD-7) scale; (IV) the volunteers were willing to provide informed consent. A total of 238 eligible subjects were screened out, and 52 subjects agreed to be enrolled in the experiment. Simple randomization method was used and all subjects as serial numbers were marked by an experimenter, and the serial numbers were randomly assigned into the experimental group and the control group by computers. Of the total patients, 26 were assigned to the experimental group (10 men and 16 women) and 26 were assigned to the control group (10 men and 16 women), and the 2 groups were aged $20.73 \pm 1.87$ and $20.62 \pm 1.79$ years, respectively, see Table 1 . Before participating in the study, all subjects were informed of the purpose of the study and the informed consent forms were signed.

\section{Research tools}

The Chinese version of the PHQ-9, a self-rating scale, was used to screen and evaluate depressive symptoms. It can be used as a screening tool to evaluate the depression status of research subjects. The reliability and validity of the Chinese college student population has been confirmed (8). There were 9 items in total, using 0 (not at all) to 3 (almost every day) grades, with total scores ranging from 0 to 27 points. A score of 0-4 indicates no depression, a score of 5-9 indicates that there may be mild depression, a score of 10-14 indicates moderate depression, a score of 15-19 indicates moderate to severe depression, and a score of 20-27 indicates severe depression (9).

The Chinese version of the GAD-7 scale is a self-rating scale used for generalized anxiety screening and symptom severity assessment (10). A total of 7 items were scored by grade 0 (not at all) to grade 3 (almost every day), with the total scores ranging from $0-21$. A score of $0-4$ indicates normal, a score of 5-9 indicates mild anxiety, a score of 10-14 indicates moderate anxiety, and a score of 15-21 indicates severe anxiety (11).

The Somatic Self-rating Scale (SSS) is used to quickly identify patients with mental disorders, which has shown 
better reliability and validity in previous studies. There are 20 items in total, of which 9 items are somatization symptom factors, 5 items are anxiety symptom factors, 4 items are depressive symptom factors, and 2 items are anxiety and depression symptom factors. Each item is scored from grade 1 (no symptoms) to grade 4 (degree of severity), with no reverse scoring.

The Chinese version of the Perceived Stress Scale (PSS-10) is currently the most widely used stress assessment tool (12). It is used to assess the uncontrollable and unpredictable experiences of an individual in life. It has good reliability and validity in the general population, depression, obsessive-compulsive disorder and other diseases. The questionnaire has 10 items, and each item is scored from 0 (never) to 4 (very common) with a total of 5 grades. The higher the score, the higher the level of stress. Items 1, 2, 3, 6, 9, and 10 indicate negative feelings and are scored positively. Items $4,5,7$, and 8 represent positive feelings and are scored negatively.

\section{Experimental design}

A pre-test and post-test study design was adopted in this two-parallel experiment and the allocation ratio is $1: 1$. The members of the experimental group were randomly divided into 3 groups, and group DBT interventions were performed 8 times, twice a week, with about 90 minutes for each intervention. The control group was given mental health education and sent a small video of psychological science popularization and an article on the official account. In the pre-test and post-test, the questionnaires for the PHQ-9, GAD-7, SSS, and PSS-10 scales were completed independently on sojump.com. The experiment time was from June to August 2020 when medical students were still at home, so the online intervention methods were applied. In order to prevent participants from having a greater psychological burden and to protect the privacy of participants, the activities were conducted using the ZHUMU video conferencing software. The chief examiner informed the members that they needed to choose a solitary environment and video recording was prohibited. Mindfulness exercises and homework were sent to the group in audio and spreadsheet format, and the mindfulness practices of the participants were monitored by the main tester.

All procedures performed in this study involving human participants were in accordance with the Declaration of Helsinki (as revised in 2013). The study was approved by the ethics board of Anhui Medical University (No. 2020H009).

\section{Methods of intervention}

This intervention experiment was conducted on the theoretical basis of DBT, combined with the characteristics of medical students with anxiety and depression, the activity program was designed and implemented. The summary of the activities is shown in Table 2 .

\section{Statistical processing}

The data were processed and analyzed by SPSS 23.0. The test of homogeneity between the experimental group and the control group and the difference in the scores between the experimental group and the control group after the intervention were assessed by the independent sample $t$-test, with $\alpha=0.05$ as the test level. The scores of scales before and after the intervention were compared by a 2 (group: experimental group and control group) $\times 2$ (time: before and after intervention) repeated measures analysis of variance, and data analysis was further conducted by a post-hoc test (paired sample $t$-test). All tests were two-sided, and $\mathrm{P}<0.05$ indicated a statistically significant difference.

\section{Results}

\section{Demographic of participants}

Twenty-six were assigned to the experimental group (10 men and 16 women) and 26 were assigned to the control group (10 men and 16 women) from May 2020 to July 2020, and the 2 groups were aged $20.73 \pm 1.87$ and $20.62 \pm 1.79$ years, respectively, see Figure 1.

\section{Comparison of the scale scores between the experimental group and control group before intervention}

Before the intervention of DBT group counseling, the differences between the experimental group and the control group in the total scores and dimensions of each scale were not statistically significant $(\mathrm{P}>0.05)$, as shown in Table 3.

\section{Comparison of results between the experimental group and control group after intervention}

For the PHQ-9 scale, the results of the repeated measures analysis of variance showed that the main therapeutic 
Table 2 Activity scheme of dialectical behavior therapy

\begin{tabular}{|c|c|c|}
\hline Stage & Theme of activity & Content of activity \\
\hline Mindfulness skills & $\begin{array}{l}\text { Get to know DBT and cultivate } \\
\text { "wisdom mind" }\end{array}$ & $\begin{array}{l}\text { Mindfulness breathing exercises to understand DBT; introduce } \\
\text { mindfulness; practice mindfulness "wisdom mind" skills; share the } \\
\text { experience of the activity }\end{array}$ \\
\hline \multirow[t]{2}{*}{ Emotion regulation skills } & $\begin{array}{l}\text { Recognize emotions and describe } \\
\text { emotions }\end{array}$ & $\begin{array}{l}\text { Three-minute mindfulness awareness exercise; introduce emotions, } \\
\text { recognize emotions, and describe emotions }\end{array}$ \\
\hline & $\begin{array}{l}\text { Emotion regulation and cognitive } \\
\text { change }\end{array}$ & $\begin{array}{l}\text { Describe your emotions and mindfulness exercises; the liberation of } \\
\text { thoughts and emotions }\end{array}$ \\
\hline $\begin{array}{l}\text { Techniques of pain } \\
\text { tolerance }\end{array}$ & $\begin{array}{l}\text { Soothing relaxation and diverting } \\
\text { attention }\end{array}$ & $\begin{array}{l}\text { Warm-up of mindfulness; relaxation training techniques; } \\
\text { attention-shifting techniques }\end{array}$ \\
\hline Summary & $\begin{array}{l}\text { Retrospect the whole process of the } \\
\text { group and farewell to the group }\end{array}$ & $\begin{array}{l}\text { To value your value; share the gains, review the first small goals of the } \\
\text { group; farewell and bless each other }\end{array}$ \\
\hline
\end{tabular}

DBT, dialectical behavior group therapy; ABC, accumulate positive emotions, build mastery, cope ahead of time with emotional situations; PLEASE, treat physical illness, balance eating, avoid mood-altering substance, balance sleep, get exercise.

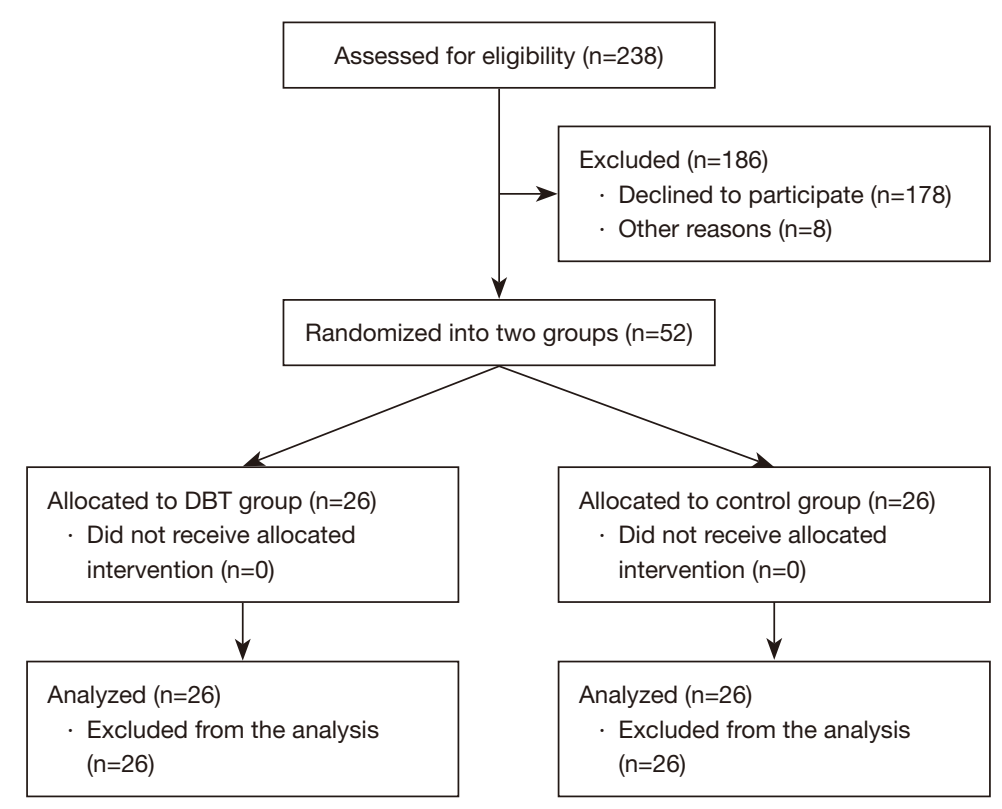

Figure 1 Flowchart. DBT, dialectical behavior therapy. 
Table 3 Comparison of pre-test data results between the experimental group and the control group $(\bar{x} \pm \mathrm{s}$, scores)

\begin{tabular}{|c|c|c|c|c|}
\hline Variables & Test group $(\mathrm{N}=26)$ & Control group $(\mathrm{N}=26)$ & $\mathrm{t}$ & $P$ \\
\hline GAD-7 & $9.81 \pm 2.20$ & $10.12 \pm 4.39$ & 0.32 & 0.751 \\
\hline Total score of SSS & $37.27 \pm 5.70$ & $36.23 \pm 5.70$ & 0.657 & 0.514 \\
\hline Somatization symptoms & $13.54 \pm 3.97$ & $13.00 \pm 3.19$ & 0.539 & 0.592 \\
\hline Depressive symptoms & $9.42 \pm 1.50$ & $8.88 \pm 1.86$ & 1.148 & 0.256 \\
\hline Anxiety and depression symptoms & $4.81 \pm 1.20$ & $5.08 \pm 1.26$ & -0.788 & 0.434 \\
\hline Total score of PSS & $18.00 \pm 4.39$ & $15.81 \pm 4.35$ & 1.808 & 0.077 \\
\hline Negative feelings & $11.23 \pm 3.69$ & $10.38 \pm 3.60$ & 0.837 & 0.407 \\
\hline
\end{tabular}

PHQ-9, Patient Health Questionnaire; GAD-7, Generalized Anxiety Disorder scale; SSS, Somatic Self-rating Scale; PSS, Perceived Stress Scale.

effect of time was significant $\left[\mathrm{F}_{(1,50)}=23.573, \mathrm{P}<0.001\right]$, the main therapeutic effect of group was significant $\left[\mathrm{F}_{(1,25)}=4.418, \mathrm{P}=0.047\right]$, and the interaction of the 2 factors was significant $\left[\mathrm{F}_{(1,50)}=6.468, \mathrm{P}=0.014\right]$. For the $\mathrm{GAD}$ 7 scale, the results of the repeated measures analysis of variance showed that the main therapeutic effect of time was significant $\left[\mathrm{F}_{(1,50)}=34.153, \mathrm{P}<0.001\right]$, while the main therapeutic effect of group was not significant $\left[\mathrm{F}_{(1,25)}=1.675, \mathrm{P}=0.202\right]$, and the interaction of the 2 factors was significant $\left[\mathrm{F}_{(1,50)}=16.163, \mathrm{P}<0.001\right.$. For the total score of the SSS, the main therapeutic effect of time was significant $\left[\mathrm{F}_{(1,50)}=15.525, \mathrm{P}<0.001\right]$, the main therapeutic effect of group was significant $\left[\mathrm{F}_{(1,25)}=0.003, \mathrm{P}=0.957\right]$, and the interaction of the 2 factors was significant $\left[F_{(1,50)}=0.890\right.$, $\mathrm{P}=0.350]$. In the dimension of somatization symptoms, the main therapeutic effect of time was not significant $\left[\mathrm{F}_{(1,50)}=1.206, \mathrm{P}=0.277\right]$, the main therapeutic effect of group was not significant $\left[\mathrm{F}_{(1,25)}=0.303, \mathrm{P}=0.585\right]$, while the interaction of the 2 factors was significant $\left[\mathrm{F}_{(1,50)}=0.036\right.$, $\mathrm{P}=0.851$. In the dimension of anxiety symptoms, the main therapeutic effect of time was significant $\left[\mathrm{F}_{(1,50)}=9.489\right.$, $\mathrm{P}=0.003]$, the main therapeutic effect of group was not significant $\left[\mathrm{F}_{(1,25)}=0.007, \mathrm{P}=0.936\right]$, and the interaction of the 2 factors was not significant $\left[\mathrm{F}_{(1,50)}=0.303, \mathrm{P}=0.585\right]$. In the dimension of depression symptoms, the main therapeutic effect of time was significant $\left[\mathrm{F}_{(1,50)}=21.081\right.$, $\mathrm{P}<0.001]$, while the main therapeutic effect of group was not significant $\left[\mathrm{F}_{(1,25)}=0.133, \mathrm{P}=0.717\right]$, and the interaction of the 2 factors was significant $\left[\mathrm{F}_{(1,50)}=4.989, \mathrm{P}=0.03\right]$. In the dimension of anxiety and depression symptoms, the main therapeutic effect of time was significant $\left[F_{(1,50)}=10.186, P=0.002\right]$, while the main therapeutic effect of group was not significant $\left[\mathrm{F}_{(1,25)}=1.731, \mathrm{P}=0.194\right]$, and the interaction of the 2 factors was not significant $\left[\mathrm{F}_{(1,50)}=0.060, \mathrm{P}=0.807\right]$. For the total score of the PSS, the main therapeutic effect of time was not significant $\left[\mathrm{F}_{(1,50)}=0.004, \mathrm{P}=0947\right]$, the main therapeutic effect of group was not significant $\left[\mathrm{F}_{(1,25)}=0.023, \mathrm{P}=0.880\right]$, while the interaction of the 2 factors was significant $\left[\mathrm{F}_{(1,50)}=5.930\right.$, $\mathrm{P}=0.018]$. In the negative dimension, the main therapeutic effect of time was significant $\left[\mathrm{F}_{(1,50)}=15.735, \mathrm{P}<0.001\right]$, while the main therapeutic effect of group was not significant $\left[\mathrm{F}_{(1,25)}=0.222, \mathrm{P}=0.640\right]$, and the interaction of the 2 factors was not significant $\left[\mathrm{F}_{(1,50)}=0.407, \mathrm{P}=0.526\right]$. In the positive dimension, the main therapeutic effect of time was significant $\left[\mathrm{F}_{(1,50)}=15.735, \mathrm{P}<0.001\right]$, while the main therapeutic effect of group was not significant $\left[\mathrm{F}_{(1,25)}=1.563\right.$, $\mathrm{P}=0.217]$, and the interaction of the 2 factors was not significant $\left[\mathrm{F}_{(1,50)}=8.348, \mathrm{P}=0.006\right]$.

The paired sample t-test (see Tables 3,4) showed that there were significant differences $(\mathrm{P}<0.05)$ in PHQ-9 $(\mathrm{t}=5.047, \mathrm{P}<0.001), \mathrm{GAD}-7(\mathrm{t}=5.651, \mathrm{P}<0.001)$, SSS total score $(t=3.889, P=0.001)$, and depressive symptoms $(t=6.814$, $\mathrm{P}<0.001)$ between the pre-test and post-test scores in the experimental group, and the scores after the intervention were lower than the scores before the intervention. There were no significant differences $(\mathrm{P}>0.05)$ in somatization symptoms $(\mathrm{t}=0.993, \mathrm{P}=0.330)$ and total scores of the PSS $(\mathrm{t}=1.696, \mathrm{P}=0.102)$. PHQ-9 $(\mathrm{t}=1.699, \mathrm{P}=0.102), \mathrm{GAD}-7$ $(\mathrm{t}=1.868, \mathrm{P}=0.074)$, total scores of SSS $(\mathrm{t}=1.812, \mathrm{P}=0.082)$, 
Table 4 Comparison of the pre-test and post-test scores in the experimental group $(\bar{x} \pm \mathrm{s}$, scores)

\begin{tabular}{|c|c|c|c|c|}
\hline Variables & Pre-test & Post-test & $\mathrm{t}$ & $\mathrm{P}$ \\
\hline GAD-7 & $9.81 \pm 2.21$ & $5.23 \pm 3.64$ & 5.651 & 0.000 \\
\hline Total score of SSS & $37.27 \pm 5.70$ & $32.42 \pm 6.74$ & 3.889 & 0.001 \\
\hline Somatization symptoms & $13.54 \pm 3.97$ & $12.88 \pm 3.33$ & 0.993 & 0.330 \\
\hline Total score of PSS & $18.00 \pm 4.39$ & $15.96 \pm 4.19$ & 1.696 & 0.102 \\
\hline
\end{tabular}

PHQ-9, Patient Health Questionnaire; GAD-7, Generalized Anxiety Disorder scale; SSS, Somatic Self-rating Scale; PSS, Perceived Stress Scale.

Table 5 Comparison of the pre-test and post-test scores in the control group $\left(\bar{x}_{ \pm s}\right.$, scores)

\begin{tabular}{|c|c|c|c|c|}
\hline Variables & Pre-test & Post-test & $\mathrm{t}$ & $\mathrm{P}$ \\
\hline GAD-7 & $8.85 \pm 2.56$ & $8.00 \pm 3.48$ & 1.868 & 0.074 \\
\hline Total score of SSS & $36.23 \pm 5.70$ & $33.31 \pm 6.90$ & 1.812 & 0.082 \\
\hline Somatization symptoms & $13.00 \pm 3.19$ & $12.54 \pm 3.17$ & 0.597 & 0.556 \\
\hline Total score of PSS & $16.04 \pm 4.41$ & $18.19 \pm 4.81$ & -1.748 & 0.093 \\
\hline
\end{tabular}

PHQ-9, Patient Health Questionnaire; GAD-7, Generalized Anxiety Disorder scale; SSS, Somatic Self-rating Scale; PSS, Perceived Stress Scale.

somatization symptoms $(\mathrm{t}=0.597, \mathrm{P}=0.556)$, depressive symptoms $(\mathrm{t}=1.362, \mathrm{P}=0.185)$, and total scores of the PSS $(\mathrm{t}=-1.748, \mathrm{P}=0.093)$ were not significantly different $(\mathrm{P}>0.05)$ in the control group, see Tables 4,5.

\section{Comparison of the value-added pre-test and post-test scores in the experimental group and the control group}

The pre-test scores were subtracted from the post-test scores to obtain the value-added scores of the difference between the pre-test scores and post-test scores, and the independent sample $t$-test was performed on the 2 groups of pre-test scores (refer to Table 6). The score increase of the experimental group on the PHQ-9 and GAD-7 scales was significantly higher than that of the control group $(\mathrm{P}<0.05)$. For the SSS scale, the score increase of the experimental group on the depressive symptom subscale was significantly higher than that of the control group $(\mathrm{P}<0.05)$, but there was no significant difference between the 2 groups in the total score, the anxiety symptom subscale, and the anxiety and depression symptom subscale $(\mathrm{P}>0.05)$. In the total score of the PSS scale, the experimental group had a significant increase compared with the control group
$(\mathrm{P}<0.05)$. In the negative perception subscale, there was no significant difference between the 2 groups $(\mathrm{P}>0.05)$. In the positive perception subscale, the value-added score of the control group was significantly higher than that of the experimental group $(\mathrm{P}<0.05)$.

\section{Discussion}

There are relevant reviews on the application of DBT in China. However, there are few intervention studies, and the targets of intervention are concentrated on suicidal selfinjury behavior and eating disorders $(13,14)$. There are few studies on the application of DBT in college psychological consultation and counseling (emotion regulation), and there is a lack of localized programs and empirical analysis of DBT in China. In this study, DBT was applied for anxiety and depression in medical students during the normalization of epidemic prevention and control. As far as we know, there is no similar study in China.

The results of this study showed that before the DBT intervention, the experimental group and the control group showed no significant differences in the total scores and various dimensions of the PHQ-9, GAD-7, SSS, and 
Table 6 Comparison between the experimental group and the control group before and after measuring the value-added score results $(\bar{x} \pm \mathrm{s}$, points)

\begin{tabular}{|c|c|c|c|c|}
\hline Variables & Experimental group & Control group & $\mathrm{t}$ & $\mathrm{P}$ \\
\hline GAD-7 & $4.54 \pm 4.1$ & $1.08 \pm 2.21$ & 3.790 & 0.000 \\
\hline Total score of SSS & $4.85 \pm 6.35$ & $2.92 \pm 8.23$ & 0.943 & 0.350 \\
\hline Somatization symptoms & $0.65 \pm 3.36$ & $0.46 \pm 3.94$ & 0.189 & 0.851 \\
\hline Depressive symptoms & $2.12 \pm 1.58$ & $0.73 \pm 2.74$ & 2.234 & 0.030 \\
\hline Anxiety and depression symptoms & $0.81 \pm 1.625$ & $0.69 \pm 1.76$ & 0.246 & 0.807 \\
\hline Total score of PSS & $2.04 \pm 6.13$ & $-2.15 \pm 6.29$ & 2.435 & 0.018 \\
\hline Negative feelings & $3.19 \pm 4.58$ & $2.31 \pm 5.39$ & 0.638 & 0.526 \\
\hline
\end{tabular}

PHQ-9, Patient Health Questionnaire; GAD-7, Generalized Anxiety Disorder scale; SSS, Somatic Self-rating Scale; PSS, Perceived Stress Scale.

PSS scales, indicating that the experimental group was matched with the control group. After the intervention, the scores of the PHQ-9 and GAD-7 scales in the experimental group were significantly lower than those of the control group, and the total scores of the depression symptom subscale on the SSS scale and PSS scale were also significantly reduced, which indicates that DBT can improve negative emotions such as depression and anxiety. These results are consistent with the results of previous DBT interventions on depression and anxiety. Studies have shown that DBT treatment effectively reduces the anxiety and depression levels of subjects $(15,16)$. The reasons may be related to the following aspects: (I) DBT has a reliable theoretical foundation and a supporting treatment framework, and appropriate program design and intervention goals were completed under the framework. The intervention scheme of the study was aimed at the anxiety and depression of medical students. Meanwhile, considering the high academic pressure and stress experienced by medical students, the intervention scheme was designed on the basis of adjustment and modification that meets the current actual needs with reference to domestic and foreign intervention schemes (17-20), which is systematic, complete, and pertinent. (II) The age, the level of awareness of COVID-19, the change in future health behaviors were associated with anxiety and depression among the students. Emphasis was placed on mindfulness and cognitive changes to regulate emotions by observing, describing, and participating without judgment, changing the cognitive styles of participants, developing listening, expression, consultation, negotiation, and other communication skills, learning to control impulsive behavior and fundamentally accept difficult life events during stress, reducing emotional vulnerability, and improving their negative emotional state. (III) During the epidemic, medical students rarely communicated with teachers and classmates at home, resulting in a lack of smooth information transmission. Active interaction among members of the group can form a good communication atmosphere and a trusting and supportive group environment, which can effectively alleviate the anxiety and depression caused by the epidemic.

DBT group counseling was developed on the basis of traditional cognitive behavior therapy. Its group skills training includes mindfulness skills, emotion regulation skills, pain tolerance skills, and interpersonal effectiveness skills. It emphasizes the application of cognitive changes and numerous behavioral therapy techniques combined with mindfulness skills to help subjects learn to maintain a balance between acceptance and change $(4,21)$. Compared with other therapies, DBT has its own unique advantages. The stable relationship between the therapist and the subjects is emphasized in DBT (22), which helps to consolidate the therapeutic relationship. Meanwhile, DBT has a lower dropout rate (23), which indicates that subjects have a higher acceptance of DBT.

In this study, DBT group counseling did not significantly reduce the somatization symptoms of the SSS scale. The reasons may be that the pre-test somatization symptom scores of the experimental group and the control group 
were not high, which caused no significant difference in the post-hoc test. It may also be caused by smaller change gap among the professional knowledge reserves and awareness of medical students than college students in other majors during the epidemic, with the correct understanding of their own physical discomfort.

After the outbreak of the COVID-19 epidemic, the psychological and behavioral status of many medical students changed, with many emotional problems. Many medical students do not know how to deal with negative emotions. Online video software was applied in the intervention experiment, in which subjects can log in on a smart phone or computer to participate, which not only ensures the normal progress of the activity, but also protects the privacy of the subjects. In this experimental intervention, the mindfulness activity was conducted with the mindfulness manuscript recorded and sent by the test leader to the subjects in the form of audio, which was simple and easy to operate. Online group counseling may face some additional obstacles compared with face-toface counseling, such as the internet lagging from time to time, some insecurity in turning on the camera during the initial activity, inability to feel the somatic presence of group members, and the lack of a maintenance environment and eye contact, among others. However, it provides a better way for medical students to access psychological consultation and counseling services during the epidemic.

In conclusion, DBT group counseling can effectively alleviate the anxiety and depression of medical students during the normalization of epidemic prevention and control. In the future, DBT group counseling can be used in school psychological consultation and psychological counseling to alleviate the negative emotions of college students. Furthermore, it can help to regulate emotions and better meet the psychological needs of medical students and the development needs on the situation of college psychological counseling.

\section{Acknowledgments}

Funding: Research on the Intervention Effect of Mindfulness and Cognitive Behavioral Therapy on the Anxiety and Depression of University Students Caused by the Epidemic (2020-AYDYQ-008).

\section{Footnote}

Reporting Checklist: The authors have completed the
CONSORT reporting checklist. Available at https://dx.doi. org/10.21037/apm-21-2466

Trial Protocol: Available at https://dx.doi.org/10.21037/apm21-2466

Data Sharing Statement: Available at https://dx.doi. org/10.21037/apm-21-2466

Conflicts of Interest: All authors have completed the ICMJE uniform disclosure form (available at https://dx.doi. org/10.21037/apm-21-2466). The authors have no conflicts of interest to declare.

Ethical Statement: The authors are accountable for all aspects of the work in ensuring that questions related to the accuracy or integrity of any part of the work are appropriately investigated and resolved. All procedures performed in this study involving human participants were in accordance with the Declaration of Helsinki (as revised in 2013). The study was approved by the ethics board of Anhui Medical University (No. 2020H009) and informed consent was obtained from all the subjects.

Open Access Statement: This is an Open Access article distributed in accordance with the Creative Commons Attribution-NonCommercial-NoDerivs 4.0 International License (CC BY-NC-ND 4.0), which permits the noncommercial replication and distribution of the article with the strict proviso that no changes or edits are made and the original work is properly cited (including links to both the formal publication through the relevant DOI and the license). See: https://creativecommons.org/licenses/by-nc-nd/4.0/.

\section{References}

1. Wang X, Hegde S, Son C, et al. Investigating Mental Health of US College Students During the COVID-19 Pandemic: Cross-Sectional Survey Study. J Med Internet Res 2020;22:e22817.

2. Chang J, Yuan Y, Wang D. Mental health status and its influencing factors among college students during the epidemic of COVID-19. Nan Fang Yi Ke Da Xue Xue Bao 2020;40:171-6.

3. Lasheras I, Gracia-García P, Lipnicki DM, et al. Prevalence of Anxiety in Medical Students during the COVID-19 Pandemic: A Rapid Systematic Review with Meta-Analysis. Int J Environ Res Public Health 2020;17:6603. 
4. Linehan MM. Cognitive-behavioral treatment of borderline personality disorder. J CurrPsychiatry Rep 1993;6:225-31.

5. Neacsiu AD, Linehan MM. Dialectical behavior therapy for borderline personality disorder. In: Barlow DH. editor. Clinical handbook of psychological disorders. 5th ed. New York: Guilford Press, 2016: 394-461.

6. Stone MH. Borderline Personality Disorder: Clinical Guidelines for Treatment. Psychodyn Psychiatry 2019;47:5-26.

7. Kröger C, Schweiger U, Sipos V, et al. Effectiveness of dialectical behaviour therapy for borderline personality disorder in an inpatient setting. Behav Res Ther 2006;44:1211-7.

8. Zhang YL, Liang W, Chen ZM, et al. Validity and reliability of Patient Health Questionnaire-9 and Patient Health Questionnaire-2 to screen for depression among college students in China. Asia Pac Psychiatry 2013;5:268-75.

9. Kroenke K, Spitzer RL, Williams JB. The PHQ-9: validity of a brief depression severity measure. J Gen Intern Med 2001;16:606-13.

10. Schalet BD, Cook KF, Choi SW, et al. Establishing a common metric for self-reported anxiety: linking the MASQ, PANAS, and GAD-7 to PROMIS Anxiety. J Anxiety Disord 2014;28:88-96.

11. Spitzer RL, Kroenke K, Williams JB, et al. A brief measure for assessing generalized anxiety disorder: the GAD-7. Arch Intern Med 2006;166:1092-7.

12. Lu W, Bian Q, Wang W, et al. Chinese version of the Perceived Stress Scale-10: A psychometric study in Chinese university students. PLoS One 2017;12:e0189543.

13. Yang X, Liu D, Wang Y, et al. Effectiveness of ZhongYong thinking based dialectical behavior therapy group skills training versus supportive group therapy for lowering suicidal risks in Chinese young adults: A randomized controlled trial with a 6-month follow-up. Brain Behav 2020;10:e01621.

Cite this article as: Liang $\mathrm{L}$, Feng $\mathrm{L}$, Zheng X, Wu Y, Zhang C, Li J. Effect of dialectical behavior group therapy on the anxiety and depression of medical students under the normalization of epidemic prevention and control for the COVID-19 epidemic: a randomized study. Ann Palliat Med 2021;10(10):10591-10599. doi: 10.21037/apm-21-2466
14. Chen J, Guo L, Gu L, et al. The introduction of treatment and the cultural adaptability of western psychotherapies for eating disorders in China. Int J Eat Disord 2021;54:102-6.

15. Bohus M, Haaf B, Simms T, et al. Effectiveness of inpatient dialectical behavioral therapy for borderline personality disorder: a controlled trial. Behav Res Ther 2004;42:487-99.

16. Saito E, Tebbett-Mock AA, McGee M. Dialectical Behavior Therapy Decreases Depressive Symptoms Among Adolescents in an Acute-Care Inpatient Unit. J Child Adolesc Psychopharmacol 2020;30:244-9.

17. Neacsiu AD, Eberle JW, Kramer R, et al. Dialectical behavior therapy skills for transdiagnostic emotion dysregulation: a pilot randomized controlled trial. Behav Res Ther 2014;59:40-51.

18. Lee S, Mason M. Effectiveness of Brief DBT-informed Group Therapy on Psychological Resilience: A Preliminary Naturalistic Study. Journal of College Student Psychotherapy 2019;33: 25-37.

19. Muhomba M, Chugani CD, Uliaszek AA, et al. Distress Tolerance Skills for College Students: A Pilot Investigation of a Brief DBT Group Skills Training Program. Journal of College Student Psychotherapy 2017;31:247-56.

20. Chugani CD, Ghali MN, Brunne J. Effectiveness of Short Term Dialectical Behavior Therapy Skills Training in College Students with Cluster B Personality Disorders. Journal of College Student Psychotherapy 2013;27:323-36.

21. Linehan MM. Skills training manual for treating borderline personality disorder. New York, NY: Guilford Press, 1993.

22. Neacsiu AD, Linehan MM. Dialectical behavior therapy for borderline personality disorder. New York: Guilford Press, 2014: 19.

23. Uliaszek AA, Rashid T, Williams GE, et al. Group therapy for university students: A randomized control trial of dialectical behavior therapy and positive psychotherapy. Behav Res Ther 2016;77:78-85.

(English Language Editor: C. Betlazar-Maseh) 